\title{
Self-management in patients with COPD: theoretical context, content, outcomes, and integration into clinical care
}

This article was published in the following Dove Press journal:

International Journal of COPD

I September 2014

Number of times this article has been viewed

\section{Ad A Kaptein \\ Maarten J Fischer \\ Margreet Scharloo}

Medical Psychology Section, Leiden University Medical Centre (LUMC), Leiden, the Netherlands

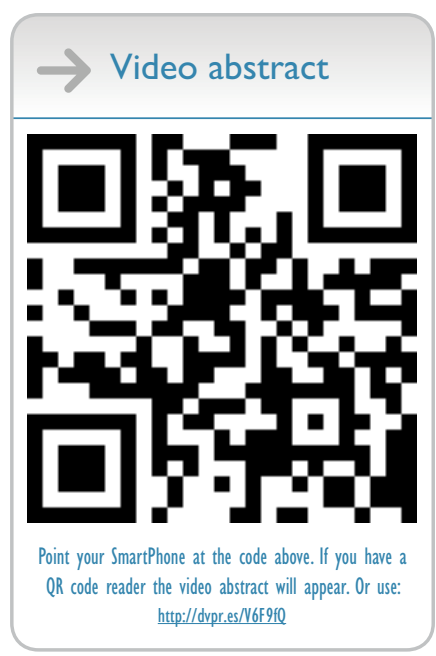

Correspondence: Ad A Kaptein Medical Psychology Section,

Leiden University Medical Center,

2 Albinusdreef, PO Box 9600 ,

Leiden 2300 RC, the Netherlands

$\mathrm{Tel}+3$ I 7| 5262905

Email a.a.kaptein@lumc.nl
Abstract: In this narrative review, we put self-management in the context of a 50-year history of research about how patients with COPD respond to their illness. We review a definition of self-management, and emphasize that self-management should be combined with disease management and the chronic care model in order to be effective. Reviewing the empirical status of self-management in COPD, we conclude that self-management is part and parcel of modern, patient-oriented biopsychosocial care. In pulmonary rehabilitation programs, self-management is instrumental in improving patients' functional status and quality of life. We conclude by emphasizing how studying the way persons with COPD make sense of their illness helps in refining self-management, and thereby patient-reported outcomes in COPD.

Keywords: chronic obstructive pulmonary disease, self-management, psychology, quality of life, biopsychosocial model, medical humanities

\section{Introduction}

It was 45 years ago that the picture below (Figure 1) was published in a paper titled "Outpatient care for patients with chronic airway obstruction - emphysema and bronchitis". ${ }^{1}$ The caption for the figure in the paper reads: "Nurse giving small group education class to CAO patients at beginning of their comprehensive care program". A number of features of the picture are striking: the patients are totally passive, the nurse in front of the blackboard is explaining a pathophysiological phenomenon, a head nurse is checking whether the patients are paying attention (and one is wondering whether the nurse is doing her job adequately). It is understandable how 45 years ago, different views dominated the area of self-management for people with chronic medical conditions, so we do not mean any disrespect regarding these efforts. Nevertheless, it makes a modern medical psychologist with knowledge regarding this issue cringe: all elements in the picture fly in the face of current views on addressing self-management in persons with COPD.

We examine whether self-management in patients with COPD in 2014 produces pictures that differ considerably from the one in Figure 1. We analyze treatment strategies regarding self-management in patients with COPD, review the methods applied in encouraging self-management behaviors, the efficacy and outcomes of self-management programs on quality of life (QOL) and behavioral outcomes, and touch upon how selfmanagement may be incorporated into regular medical care for people with COPD.

Rather than adding another review of the literature on self-management in patients with COPD, we intend to provide the reader with a wake-up call. Compared to self-management in patients with other chronic illnesses (eg, cardiovascular disease, diabetes, oncology), research regarding self-management in patients with COPD lags 


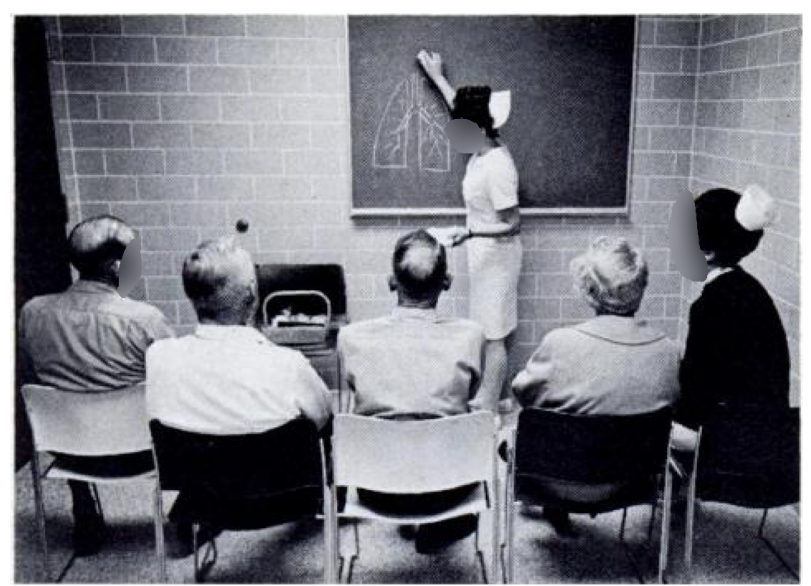

Figure I "Nurse giving small group education class to CAO patients at beginning of their comprehensive care program".

Note: Copyright (C) 197I. The American College of Chest Physicians. Reproduced with permission from the American College of Chest Physicians. Neff TA, Petty TL. Outpatient care for patients with chronic airway obstruction - emphysema and bronchitis. Chest. 1971;60 Suppl: I IS-17S.'

behind considerably. Recommendations about increasing the knowledge of patients with COPD about their disease is a naïve and biomedical view on the complex issue of behavior change. Biomedical knowledge about COPD (or any topic, for that matter) is perishable. Encouraging patients to adopt current knowledge merely reflects the imbalance of power between medical doctors and patients. In addition, knowledge does not impact on illness behavior. Therefore, self-management must encompass cognitions (views, ideas) and emotions (eg, embarrassment, shame, anger) that do impact on coping and QOL. ${ }^{2}$ A much-cited study by Fan et al seems to illustrate this point: providing patients with education and action plans is woefully inadequate. ${ }^{3}$ Our point is beautifully illustrated in a paper by Wagg (Figure 2). ${ }^{4}$ Action plans and education are only the first steps in a comprehensive strategy of improving the well-being of persons with COPD.

Recently, highly interesting shifts in discussions about outcomes in medical care have been published. In a paper by Huber et al, the authors proposed defining the crucial outcome of medical care as "the ability to adapt and to self manage". 5 Focusing on so-called objective outcome measures (eg, forced expiratory volume in 1 second, 6-minute walk distance) is a sad mistake: there are no objective measures in medicine. ${ }^{6}$

\section{Current treatment strategies in COPD: where is "self- management"?}

A March 4, 2014 PubMed search for "COPD and selfmanagement" produced 1,130 hits. The results of identical

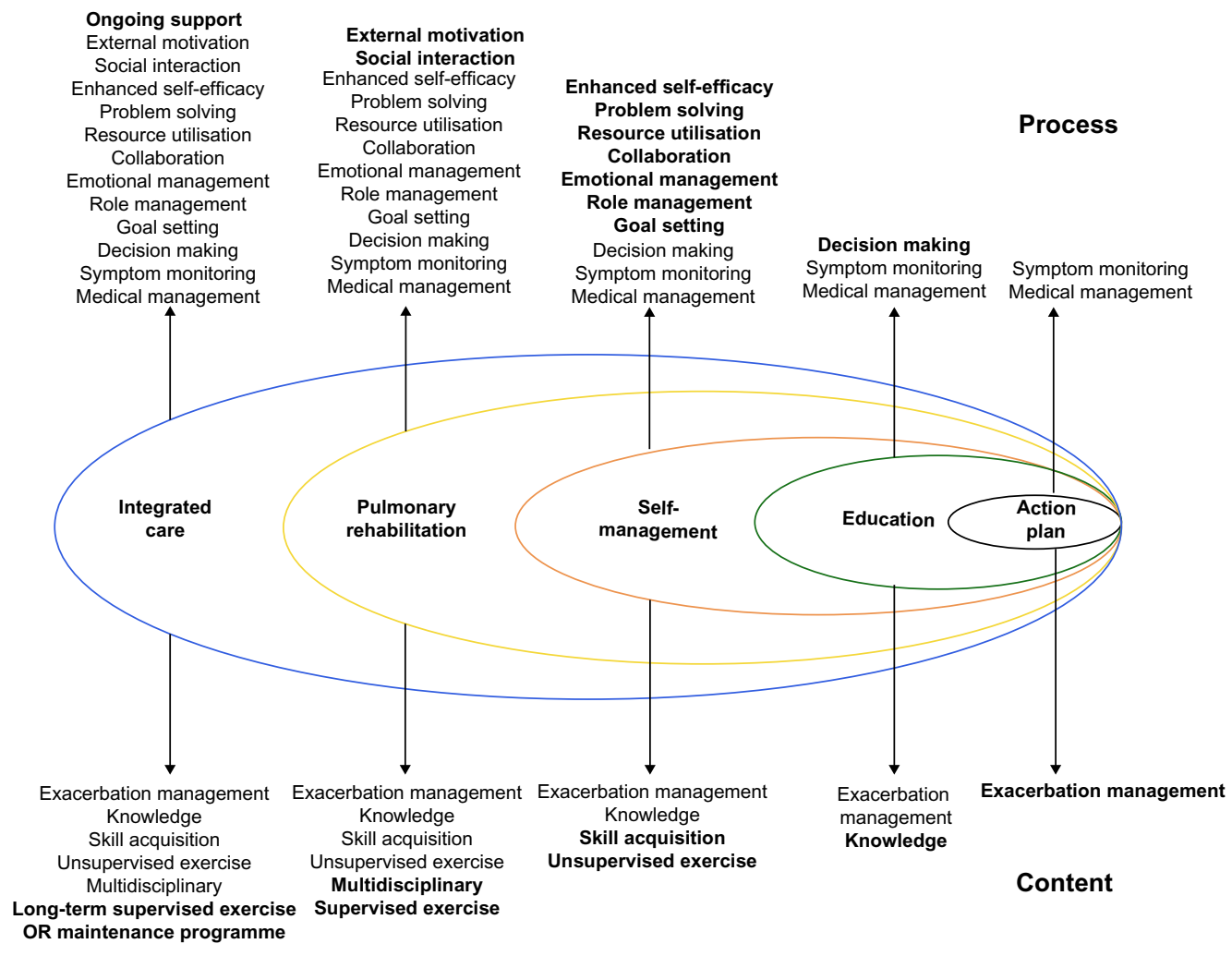

Figure 2 "A spectrum of support for chronic obstructive pulmonary disease (COPD)".

Note: Copyright (C) 2012 SAGE Publications. Reprinted by permission of SAGE Publications. Wagg K. Unravelling self-management for COPD. What next? Chron Respir Dis. 20I2;9:5-7.4 
searches for three other chronic somatic diseases reflected meaningful differences from the COPD search: asthma 3,233, cancer 10,990, and diabetes mellitus 13,142 hits. These numbers demonstrate two points: self-management is a relatively underresearched topic in patients with COPD compared to patients with other chronic illnesses, and the rather optimistic tone in papers on the effects of self-management in patients with COPD seems unwarranted. Pleas for further research on this topic appear to be quite justified. In this context, it is striking to see that "self-management" is not included in the GOLD (Global initiative for chronic Obstructive Lung Disease) guidelines for diagnosis and management of patients with COPD. When one searches carefully for behavioral issues in the guidelines on the fourth-leading cause of illness and death, one will find some lip service to this topic in the paragraphs on pulmonary rehabilitation (PR) and palliative care in those guidelines only.

Before reviewing the effects of self-management for patients with COPD, we will briefly sketch the precursors of self-management for people with respiratory problems. This will set the scene for a review of methods and outcomes of self-management in persons with COPD.

The first empirical study by a psychologist of persons with COPD was published in $1961 .{ }^{8}$ Using the Szondi test, a personality-characteristics test, the researchers compared a sample of 33 patients with emphysema with two other samples: hospitalized patients and persons from the healthy population. It was found that the COPD patients scored more highly on indicators of psychopathology and personality disorders. These findings must be interpreted with great caution, as modern-day medical psychologists question the value of the test used. We mention the paper here to illustrate the progress made in 50 years in behavioral research on patients with COPD: sounder theoretical models, less selection bias, higher-quality psychometrics, and better statistical analysis.

The first paper on the effects of an intervention that with some restrictions could be labeled "self-management" was published in 1973 by Agle et al. ${ }^{9}$ In a before-after design without a control group, a sample of 21 patients with COPD participated in a 4-week in-hospital multidisciplinary treatment program, which encompassed group therapy and vocational and social counseling aimed at "... improved response to exercise stress, improved life adjustment and vocational achievement when appropriate". Positive effects were observed, which - it seems to the surprise of the authors - did not correlate with physical characteristics, but with psychological ones: “... of particular importance in affecting positive change appeared to be the desensitization of the fear of dyspnea and increased autonomy in the control of symptoms". These are fascinating results, predating research findings in PR programs some 30-40 years later.

In Denver, Colorado, a research group of psychologists, collaborating with respiratory physicians, developed an important research line, which they labeled "psychomaintenance". The scientists observed how behavioral styles - and not clinical characteristics, such as pulmonary function predicted medical outcome, operationalized as length of hospitalization, severity of medication at discharge, and risk of rehospitalization. This was observed in patients with asthma in a third-line medical facility. The researchers extended their work to patients with COPD, and published a paper that most likely would have been very useful in helping lay the foundation for self-management in COPD,${ }^{10}$ in that it identified illness perceptions and coping as determinants of outcome in COPD care. However, before they could put their findings to the test in intervention research, the research group was dismissed, most likely because of the gap between behavioral research and biomedical research, a problem that still seems to threaten the implementation of self-management in regular medical care for persons with COPD.

It is surprising for current researchers in the area of self-management for patients with COPD to qualify a study from 1984 as one of the best till now on the topic. Atkins et $\mathrm{al}^{11}$ demonstrated how a cognitive-behavioral intervention increased physical exercise, which in turn improved QOL and self-efficacy for walking in a fairly large sample of people with COPD. Briefly, patients met individually with a psychology student, who delivered one of five intervention formats. In the cognitive-modification condition, patients' statements about physical activity were monitored, challenged, and modified, from negative to more appropriate positive and goaloriented self-statements. For example, “I can't walk very far without getting short of breath, so what's the use?" to "This walking is uncomfortable, but I can handle it. Soon I will be able to walk farther." The cognitive-modification condition produced significant and clinically relevant improvements in exercise capacity and QOL compared to the other conditions, supporting the value of addressing cognitions and emotions in patients with COPD.

Research following up on this cognitive-behavioral approach to patients with COPD consistently demonstrated how cognitions and emotions play a pivotal role in the manner in which persons with COPD make sense of their illness and its medical management. This is true for patients with any 
chronic physical illness, for that matter. ${ }^{12}$ These cognitions and emotions are conceptualized as "illness perceptions" in the common sense model, a theoretical model in medical psychology that examines the relationships between the elements in Figure 3, ${ }^{13}$ with QOL as the outcome.

The crucial issue is the concepts linking sociodemographic and clinical characteristics on the one hand, and outcome on the other. Pulmonary function has an effect on QOL if the patient perceives the affected pulmonary function as limiting him/her in daily activities. Illness perceptions with more "... appropriate positive and goal directed self-statements" (compared with Atkins et al, ${ }^{11}$ ) predict a higher QOL. In our group, we provided evidence for this statement. ${ }^{14-19}$

This historical sketch covers the period between 1961 and 2014. It reflects a research tradition of more than 50 years of behavioral work on persons with COPD: from outdated psychoanalytic notions, ${ }^{8,9}$ through the work of Kinsman et al, ${ }^{10}$ Atkins et al, ${ }^{11}$ our group, ${ }^{14-19}$ and others. We have come a long way, but it seems that cognitive-behavioral approaches contribute most to improving the QOL of persons with COPD. We discuss recent research on this topic in the second part of this paper.

\section{Self-management: definition, components, effects, applications in COPD}

The term "self-management" is used rather loosely, particularly in publications in the medical world. Quite often, self-management is used as another word for "education" and "giving information", a tragic mistake, as information does not impact behavior, and knowledge about a disease is uncorrelated with patients' behavior. ${ }^{2}$ The picture of the poor COPD patients who must passively listen to a nurse who explains how air is going in and out of lungs is an illustration of the information fallacy adhered to by many medically oriented health care providers.

A definition of self-management that has proven to be helpful and clear is given by Barlow et al: ${ }^{20}$

“... manage the symptoms, treatment, physical and psychosocial consequences and life style changes inherent in living with a chronic condition. ... [the] ability to monitor one's condition and to effect the cognitive, behavioural and

sociodemographic characteristics $\rightarrow$ clinical characteristics emotional responses necessary to maintain a satisfactory quality of life", ${ }^{20}$

Two elements stand out in this definition. The first is the emphasis on adopting the patient's point of view: it is not a medicocentric view on "what ill persons must do". Second, it is an agenda for health care providers, patients, and their partners to encourage patients to acquire and apply skills in their management of their illness. These skills pertain to:

- gathering information

- managing medication

- managing symptoms

- managing psychological consequences

- adjusting lifestyle

- using social support

- communicating effectively.

Note how only one out of the seven skills is related to "information".

Self-management fits perfectly with modern views on human behavior, and on how health care can contribute to improving QOL in patients with chronic physical illness. A recent paper beautifully analyzes shifts in outcomes in health care. ${ }^{5}$ No longer should the health care system, according to the authors of the paper, strive for "complete well-being". Instead, the authors propose that health should be formulated as "the ability to adapt and to self manage". 5 In Figure 4, this shift is depicted.

A concise explanation of Figure 4 is that in all chronic somatic illnesses, some 50 years ago behavioral sciences, behavioral scientists, and clinicians explored the possible contribution of psychological factors in the causation of those illnesses - "psychosomatics". A study by Webb and Lawton ${ }^{8}$ fits within this category. Neuropsychological consequences of COPD were already the object of research and clinical intervention in the 1960s. ${ }^{21}$ QOL started to be explored with the development of questionnaires to assess this elusive concept (eg, Guyatt et $\mathrm{al}^{22}$ ). Patient education, thought to be an important goal in clinical care for persons with COPD, sparked a wealth of research. However, as stated before, patient education is a medicocentric, paternalistic approach to a behavioral issue, and thus biomedical approaches will fail. "Coping and illness perceptions" set the stage for true patient involvement, ie, for self-management. Self-management is not an isolated idea or

illness $\rightarrow$ coping $\rightarrow$ outcome (QOL)

Figure 3 A concise representation of the common sense model. 


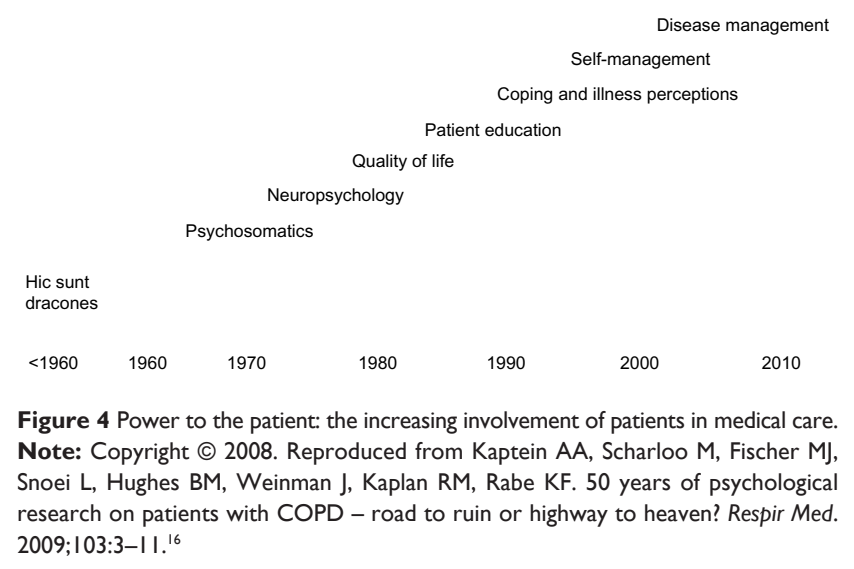

concept. This is why "Disease management" comes into play in Figure 4, not only in medical care for patients with COPD but in medical care for patients with any somatic chronic illness. ${ }^{23}$ Disease management is defined as "... an approach to patient care that emphasizes coordinated, comprehensive care along the continuum of disease and across health care delivery systems", where "... patient counseling and education, coordination, and standardization of care are key components of diseasemanagement programs". ${ }^{24}$ Clearly, "patient counseling" and education are incorporated in medical care. In their systematic review and meta-analysis of the effectiveness of COPD disease-management programs, Peytremann-Brideveaux et al concluded that: "COPD disease management programs modestly improved exercise capacity, health-related quality of life, and hospital admissions, but not all-cause mortality". ${ }^{23}$

A final concept needs mentioning: chronic care management (CCM), described by Bodenheimer et al as "the delivery of health care taking place within the entire community ... the health care system, and the provider organization ... CCM identifies six essential elements: community resources and policies, health care organization, self-management support, delivery system design, decision support, and clinical information systems" ${ }^{\prime 25}$ - see Figure 5. CCM incorporates self-management, disease management, and organizational conditions that try and make sure that self-management programs result in improvements for patients, the health care system, and society.

Adams et al published a systematic review of CCM in COPD prevention and management, and concluded that: “... patients with COPD who received interventions with 2 or more CCM components had lower rates of hospitalizations and emergency unscheduled visits and a shorter length of stay compared with control groups". ${ }^{26}$ In an earlier publication, we reviewed the evidence for the effects of self-management in the context of disease management or CCM, or not - in

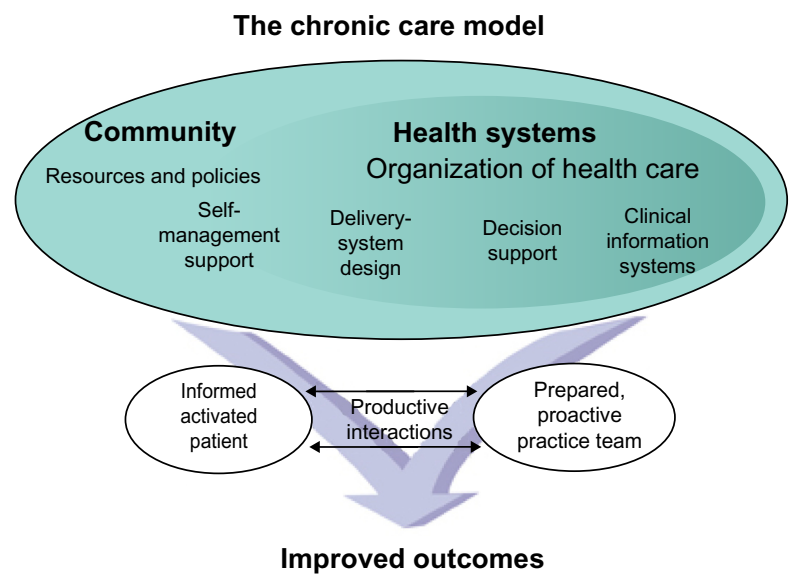

Figure 5 Chronic care model.

Note: Copyright (C) 2002. American Medical Association. All rights reserved. Reproduced from Bodenheimer T, Lorig K, Holman H, Grumbach K. Patient selfmanagement of chronic disease in primary care. JAMA. 2002;288:2469-2475. ${ }^{25}$

various chronic illnesses ${ }^{12}$ and concluded that the evidence overall is encouraging.

It is important to note how fundamentally different "self-management" is conceptualized by behavioral experts compared to authors of official statements from the American Thoracic Society (ATS) and European Respiratory Society (ERS). For example, in the 2013 publication by ATS and ERS on "key concepts and advances in pulmonary rehabilitation", educational tools concerning self-management list 15 topics, virtually all focusing on biomedical issues (eg, normal pulmonary anatomy and physiology, healthy food intake [behavioral scientists would say "eating"], role and rationale for medications, including oxygen therapy). ${ }^{27}$ Contrast these with the skills from the Barlow et al paper, ${ }^{20}$ and in publications where patients with COPD were asked to list their major concerns and needs for coaching, support, and understanding (eg, Huber et $\mathrm{al}^{5}$ ).

\section{Recent developments in COPD self-management research}

As stated before, self-management interventions in patients with COPD have been primarily associated with a health professionalcentered approach focusing on teaching patients how to use a written action plan in the event of an exacerbation and measuring outcomes such as hospital admissions and mortality. ${ }^{28,29}$ Contradictory evidence for this approach, showing benefits, ${ }^{30,31}$ but also mixed or negative results, ${ }^{32-35}$ including excess mortality, ${ }^{3}$ has recently stimulated several researchers in the field to reconsider and/or broaden the concept of self-management in $\mathrm{COPD},{ }^{36-41}$ with encouraging wording in such article titles as "reconceptualization", ${ }^{37}$ and "paradigm shift". ${ }^{38}$ 
In the most recent update of the Cochrane review on self-management interventions, the authors suggest using the term "self-management training", and explain why they removed the term "education" from the title and chose to exclude studies with education as the only active intervention: "Although patient education is an indispensable component of self-management, education alone is insufficient to achieve the goal of behavioural change". ${ }^{42}$ Overall, the results from their review show that self-management training in patients with COPD is associated with improved health-related QOL, a reduction in respiratory-related hospital admissions, and improvement in dyspnea. No effect of self- management on all-cause hospitalization, mortality, or exercise capacity was found. These (and other) authors return to the conceptualization of self-management, as described in the original work on the subject by Lorig and Holman. ${ }^{43}$ In this classic, they argue that patients with chronic illness have three lifelong self-management tasks: medical or behavioral management, life-role management, and emotional management, for which they need self-management skills much like those described by Barlow et al. ${ }^{20}$

With regard to the task of medical or behavioral management (gathering information, managing medication, managing symptoms, healthy lifestyle, communicating effectively), the contradictory outcome in COPD self-management research is fueling the conclusion that patient activation and structural behavior change should be central to the conceptualization of self-management. ${ }^{38-40,44,45}$ Consequently, interventions involving different approaches for promoting behavior change in self-management programs for patients with COPD have recently been developed, ie, motivational interviewing strategies, ${ }^{46}$ a "mindfulness for health" program, ${ }^{47}$ a self-regulation protocol, ${ }^{48}$ and an intervention tailored according to a screening instrument for personal abilities or barriers to self-management. ${ }^{49}$ Another research area is telemonitoring for patients with COPD. A recent review showed small beneficial effects from some interventions on health care utilization and health-related outcomes, ${ }^{50}$ but other interventions showed no effect at all. ${ }^{51,52}$

With respect to life-role management (using social support, leisure activities) only two COPD self-management (or rather integrated care) programs could be identified which explicitly integrated elements that offered opportunities to reduce social isolation. Moullec and Ninot examined the effects of an integrated health care program. ${ }^{53}$ Patients allocated to the intervention group joined a regional health care network that included local self-help associations of patients who had also completed PR. Coordinated sessions also included supervised psychosocial support with discussion groups. Discretionary leisure activities, such as outings, could be added if desired by members. At one year, the integrated health care program produced improvements in functional and emotional dimension scores of QOL and an increase in exercise tolerance. A study by Chavannes et al showed comparable results, with group-training sessions leading to increased social contacts (participants were encouraged to start up sporting groups with their peers). ${ }^{54}$ The integrated disease-management program produced clinically relevant and statistically significant improvements in one-year QOL in primary care COPD patients compared to usual care.

The involvement of carers in the management of patients with severe COPD/palliative care has been widely reported, but no studies could be identified that examined the feasibility of involvement of partners/significant others of less severe COPD patients in self-management. A study design has been presented in which an approach to patient care is proposed where caregivers are used to assist in the delivery of copingskills training to patients with COPD. ${ }^{55}$ This approach could be an important addition or alternative to support patients' self-management in order to improve outcomes. As Jowsey et al concluded after studying what motivates health service users with chronic illness to engage in self-management behavior: "... the significance of family as an external source of motivation suggests a need for increased investment in the knowledge and skill building of family members who contribute to care". 56

The primary focus of much of the research into emotional management (managing psychological consequences) in COPD has been on interventions reducing symptoms of anxiety and depression. A recent meta-analysis examined the comparative effectiveness of complex psychological and lifestyle interventions in reducing symptoms of anxiety and depression in patients with COPD. ${ }^{57}$ Results showed that small, nonsignificant treatment effects were found for the subgroups of trials that tested cognitive-behavioral therapy (seven included studies) and relaxation techniques (three studies). No significant difference in treatment effects was found for trials that compared self-management education with a control group. The best results were observed with programs based on multicomponent exercise training. A more recent study reported no effects of telehealth on anxiety and depression. ${ }^{52}$

A recent qualitative study explored COPD patients' goals and needs for self-management support. ${ }^{58}$ Patients reported concerns about loss of normal functioning, loss of independence, loss associated with other medical conditions, 
loss of social support, fear about disease progression, and panic when severely breathless. Desire for improved care focused on lack of self-management support and a general lack of understanding of their condition, including how to care for themselves and getting their informational and medical needs met. These findings highlight that it is about time that any self-management training program to be designed in the future should offer COPD patients (and preferably also their partners; see Gabriel et $\mathrm{al}^{59}$ ) the opportunity to learn skills to master not only the medical and behavioral tasks but also the role and emotional tasks involved in selfmanaging their disease.

\section{Pulmonary rehabilitation}

$\mathrm{PR}$ is one of the main nonpharmacologic therapies recommended for patients with COPD. ${ }^{7}$ According to the 2013 ATS/ERS consensus statement, pulmonary rehabilitation can be defined as

“... a comprehensive intervention based on a thorough patient assessment followed by patient-tailored therapies that include, but are not limited to, exercise training, education, and behavior change, designed to improve the physical and psychological condition ... and to promote the long-term adherence to health-enhancing behaviors". ${ }^{27}$

PR programs typically have an interdisciplinary character, and consist of several core components and supplementary interventions that can be used to meet the needs of the individual patient. Exercise training is considered to be the cornerstone of PR, and may include strength, endurance, and flexibility training of upper and lower limbs, and resistance training for the inspiratory muscles. ${ }^{27}$ In addition to exercise training, most PR programs comprise one or more educational modules aiming not only to increase knowledge, but more importantly to improve skills needed for effective self-management.

The emphasis on self-management within PR illustrates the growing recognition that management of the illness should be primarily a responsibility of the patient, rather than the healthcare provider. ${ }^{60}$ As illustrated by Wagg, the provision of medical information and the use of action plans for exacerbations both fall within the wider scope of self-management support. ${ }^{4}$ Self-management support within PR adopts a patientcentered approach focusing on the physical, psychological, and social domains of QOL that are affected by the illness and acknowledges the interaction between these variables. Interdisciplinary PR teams have the opportunity to combine their expertise within the (para)medical, psychological, and social areas, and thus PR programs provide a suitable platform for the delivery of self-management interventions. The goals of PR are to motivate and empower patients to cope effectively with their illness, and should not be limited to the PR program itself (eg, increase in walk distance). During PR, patients have the opportunity to learn from staff and fellow patients, and are provided with a safe environment to try out new behavior. The support and encouragement within the group setting, social learning, and the achievement of personal goals may increase patients' self-efficacy, an important condition for behavior change. ${ }^{36}$

The short-term effects of comprehensive PR programs have been examined extensively. Multidisciplinary PR programs have demonstrated significant and clinically important improvements in COPD patients' QOL, maximal and functional exercise capacity, ${ }^{61}$ symptoms of depression and anxiety, ${ }^{62}$ patients' self-efficacy, ${ }^{63,64}$ and health care use, such as number of hospital admissions, days hospitalized, and emergency room visits. ${ }^{27}$

Although the immediate effects of PR are undisputed, there is less known about the (predictors of) long-term benefits of PR. Apart from the progressive nature of COPD, patients' self-management behavior is likely to influence the degree to which gains made during PR will be sustained. In line with the aforementioned ATS/ERS statement on PR, the most rigorous review to date about self-management for patients with COPD states that the goal of self-management training should be to establish sustainable behavioral change. ${ }^{42}$ However, this review concentrated mainly on such clinical outcomes as hospital admissions, hospitalization days, use of health care facilities, medication use, lung function, and exercise capacity, whereas behavioral outcomes were not included. Few studies have investigated long-term effects of interventions on self-management behavior, such as daily physical activity ${ }^{65-67}$ and smoking cessation. ${ }^{68}$ These studies in general suggest that although longer and more intensive interventions appear to show better long-term results, patients with COPD have a high chance of relapse. Some studies have therefore investigated whether maintenance interventions after PR, consisting of several months of exercise sessions (with or without additional discussion or educational sessions), may help to sustain the benefits gained during intensive PR. Results from these studies suggest that these aftercare programs are effective in maintaining exercise capacity, but their effects on QOL are less clear. ${ }^{69}$

Consensus is emerging that self-management in PR comprises more than the transmission of knowledge. ${ }^{36}$ Psychosocial interventions, such as problem solving, 
social skills training, motivational interviewing, operant conditioning, and personal goal setting are increasingly used to influence patients' self-management behavior., ${ }^{4,27,36}$ More research is needed to determine to which degree these interventions actually contribute to changes in patients' behavior, especially in the long run. In addition, long-term follow-up studies after the completion of PR may help us to identify which patients are successful in adopting adequate self-management skills into their daily life, and which patients may benefit from ongoing professional support (integrated care).

\section{Incorporating self-management in medical care for patients with COPD}

Before embarking on the issue of incorporating theoretical and empirical knowledge about self-management into biopsychosocial care for patients with COPD, two topics deserve mention in this context. A relatively new method of eliciting patients' views about their illness relates to asking patients to draw their illness. ${ }^{70}$ Questionnaires, albeit validated, are vulnerable to socially desirable answering by patients. Asking patients to draw a picture of their illness in order to elicit patient perceptions of their illness may reduce socially desirable responses. In COPD, one study up to now is available where patients drew their illness. ${ }^{71}$ Drawings may give clinicians more insight into how patients "see" their illnesses, which may be instrumental for the clinician and patient in initiating self-management, and for addressing misconceptions about the illness and its biopsychosocial management.

Secondly, in modern medical care, the medical humanities appear to be receiving increasing attention in research and clinical care. The medical humanities attempt to integrate psychosocial issues into medical care. ${ }^{72}$ Murray recently gave a beautiful example in his paper on how opera (La Bohème, La Traviata) may help patients, partners, physicians, and other health care providers in making sense of an illness (here, tuberculosis), and in improving self-management and CCM. ${ }^{73}$ A related paper in Lancet Respiratory Medicine concluded that novels, poems, music, movies, and paintings about various respiratory illnesses may attain the same objective. ${ }^{17}$ It is quite remarkable to see how asthma, cystic fibrosis, lung cancer, and tuberculosis are represented in all five art forms; COPD is not. ${ }^{74}$

This leads us to the final topic of this paper: applying existing expertise about self-management - in a broad sense - to daily medical care for persons with COPD. Guidelines from professional organizations prescribe more or less strictly how physicians should provide quality medical care. Quite often, these guidelines identify areas that need improvement, as physicians simply do not adhere to guidelines (eg, Boulet et $\mathrm{al}^{75}$ ). These guidelines barely include issues regarding psychosocial components of care, eg, self-management. Given the evidence of the value of a biopsychosocial approach to patients with COPD (or any medical condition, for that matter), there are strong reasons to make sure the guidelines also encompass self-management, as that appears to increase the chance of patients' QOL being improved.

Four categories of professionals are involved in this undertaking: patient, partners, physician, and public (Figure 6). Implementing self-management information about COPD may very well help attain this objective. How to address those issues? A few suggestions follow.

\section{Patients}

Encourage patients to receive medical care that conforms to their wishes, needs, and worries. Patient organizations may be instrumental in empowering patients in this regard. Expert patients may be helpful here as well. Researchers may help. For example, Wortz et al explored the wishes of persons with COPD about the content and process of the medical care, with a very evident wish for psychosocial care in addition to biomedical care. ${ }^{58}$

\section{Partners of COPD patients}

These are the ones who can encourage their partners to adhere to self-management skills, at home in particular. A recent study beautifully illustrates the point. In a cross-sectional study, it was found that partners of patients with COPD per-

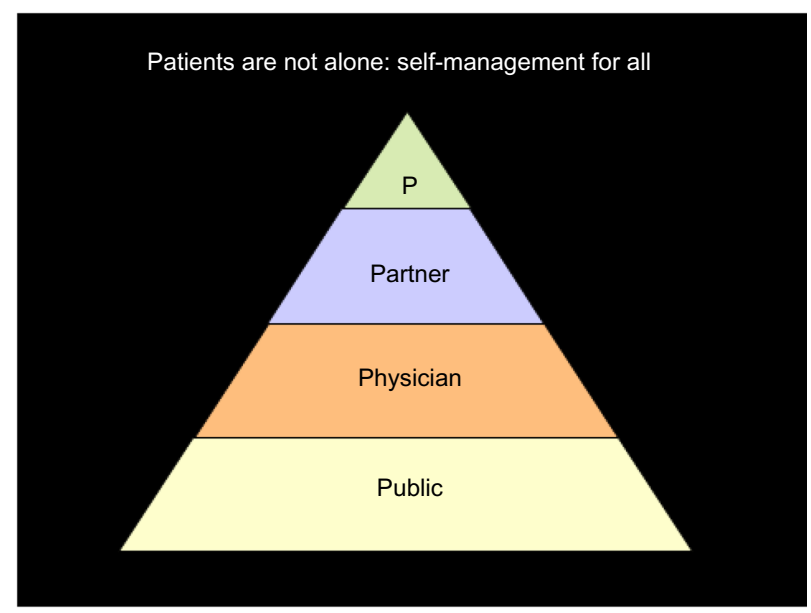

Figure 6 The four participants in self-management in chronic illness. Abbreviation: $P$, patient. 


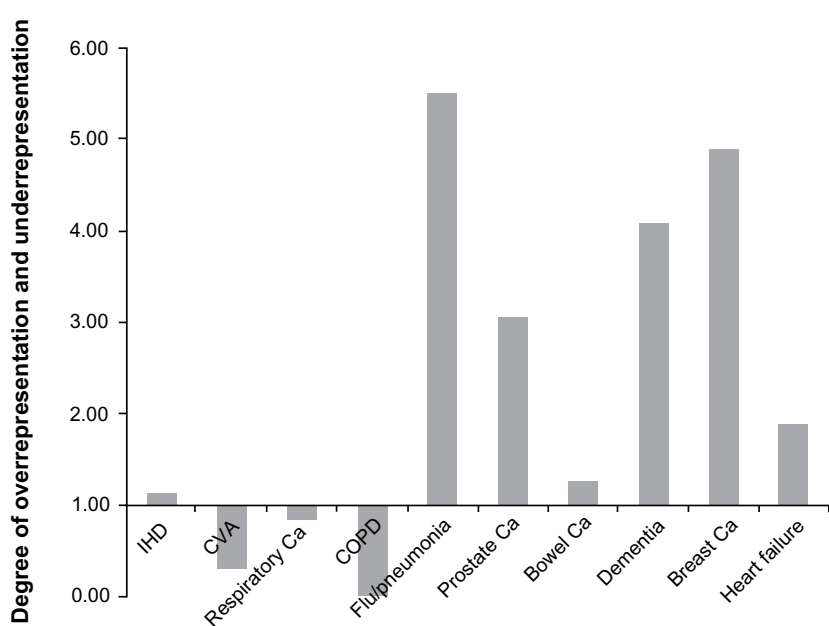

Figure 7 COPD is a highly underestimated disease.

Notes: Copyright (C) 20II Blackwell Publishing Ltd. Reproduced from Williamson JM, Skinner Cl, Hocken DB. Death and illness as depicted in the media. Int J Clin Pract. $201 \mathrm{I} ; 65: 547-551 .{ }^{78}$ Figure shows degree of overrepresentation (1.00 and higher), and underrepresentation (lower than 1.00), in UK media of the diseases, compared to real incidence of the diseases.

Abbreviations: IHD, ischemic heart disease; CVA, cardiovascular accident; Ca, cancer.

ceived the care they devoted to their partner with COPD not only represented a burden but was associated with positive experiences as well. ${ }^{76}$

\section{Physicians (and other health care providers)}

Incorporating psychosocial issues into guidelines for medical care seems to be the best way to proceed. It remains to be seen, however, whether this is a viable option..$^{5,75,77}$

\section{Public}

Recently, a study demonstrated how public perceptions of chronic illness are shaped by inadequate media attention for

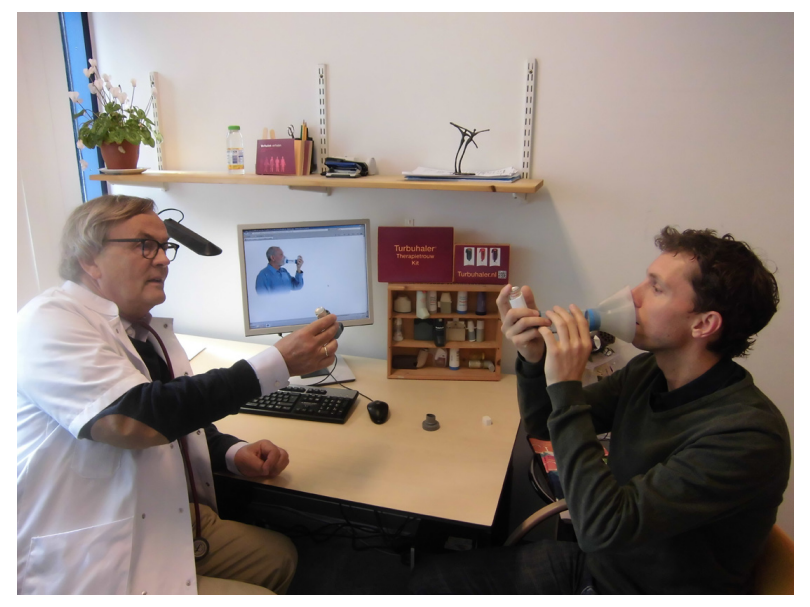

Figure 8 Health care provider demonstrating use of inhalation equipment. various diseases. ${ }^{78}$ The prevalence of breast cancer was hugely overrated; COPD was terribly underrated - see Figure 7. Patient organizations, governments, and health care insurers might do well to address this image of illness.

\section{Conclusion}

On the basis of our review, it seems that the following conclusions can be formulated in response to the four topics mentioned in the title of the paper:

1. theoretical models from the domains of coping with chronic illness, self-management and illness perceptions seem the best choice in further research about selfmanagement for persons with COPD

2. these models inform content of self-management training in COPD; rather than "educating" patients, patients must be encouraged to take control of their illness and its treatment and consequences

3. rather than focusing on biomedical outcomes (eg, forced expiratory volume in 1 second), outcomes in self-management for people with COPD should be patient-reported in terms of behavioral outcomes

4. pulmonary medicine lags behind other medical specialties in its knowledge and attitude regarding empowering patients; this situation is likely to continue for a considerable time, given the almost-negligible number of behavioral experts involved in research on persons with respiratory illnesses.

We started this narrative review with a picture from a 1971 publication: $^{1}$ a nurse demonstrating air going in and out of lungs, with four COPD-patients passively watching. Fifty years later, we had trouble in finding a picture that might illustrate 50 years' progress in self-management for people with COPD. The three authors - with quite long-standing research experience in behavioral aspects of COPD - were unable to come up with something better than the picture in (Figure 8). We still have a long way to go.

\section{Acknowledgment}

The authors acknowledge the Rijnland Rehabilitation Center, Leiden, the Netherlands, for facilitating recording the video abstract associated with this paper.

\section{Disclosure}

The authors report no conflicts of interest in this work.

\section{References}

1. Neff TA, Petty TL. Outpatient care for patients with chronic airway obstruction - emphysema and bronchitis. Chest. 1971;60 Suppl: $11 \mathrm{~S}-17 \mathrm{~S}$. 
2. Petrie KP, Weinman J. Why illness perceptions matter. Clin Med. 2006;6:536-539.

3. Fan VS, Gaziano JM, Lew R, et al. A comprehensive care management program to prevent chronic obstructive pulmonary disease hospitalizations: a randomized, controlled trial. Ann Intern Med.2012;156: 673-683.

4. Wagg K. Unravelling self-management for COPD. What next? Chron Respir Dis. 2012;9:5-7.

5. Huber M, Knottnerus JA, Green L, et al. How should we define health? BMJ. 2011;343:d4163.

6. Kaplan RM. Behavior as the central outcome in health care. Am Psychol. 1990;45:1211-1220.

7. Global initiative for chronic Obstructive Lung Disease. Global Strategy for the Diagnosis, Management, and Prevention of Chronic Obstructive Pulmonary Disease. Bethesda (MD): GOLD; 2014.

8. Webb MW, Lawton AH. Basic personality characteristics of patients with primary obstructive pulmonary emphysema. J Am Geriatr Soc. 1961;9:590-610.

9. Agle DP, Baum GL, Chester EH, Wendt M. Multidiscipline treatment of chronic pulmonary insufficiency. 1. Psychologic aspects of rehabilitation. Psychosom Med. 1973;35:41-49.

10. Kinsman RA, Yaroush RA, Fernandez E, Dirks JF, Schocket M, Fukuhara J. Symptoms and experiences in chronic bronchitis and emphysema. Chest. 1983;83:755-761.

11. Atkins CJ, Kaplan RM, Timms RM, Reinsch S, Lofback K. Behavioral exercise programs in the management of chronic obstructive pulmonary disease. J Consult Clin Psychol. 1984;52:591-603.

12. Kaptein AA, Scharloo M, Fischer MJ, Snoei L, Weinman J. Chronic obstructive pulmonary disease (COPD). In: S Newman, L Steed, K Mulligan, editors. Chronic Physical Illness: Self-Management and Behavioural Interventions. Maidenhead, UK: McGraw-Hill; 2009:255-271.

13. Leventhal H, Brissette I, Leventhal EA. The common-sense model of self-regulation of health and illness. In: Cameron LD, Leventhal H, editors. The Self-Regulation of Health and Illness Behaviour. London: Routledge; 2003:42-65.

14. Fischer MJ, Scharloo M, Abbink JJ, et al. The dynamics of illness perceptions: testing assumptions of Leventhal's common-sense model in a pulmonary rehabilitation setting. Br J Health Psychol. 2010;15:887-903.

15. Fischer MJ, Scharloo M, Abbink JJ, et al. Concerns about exercise are related to walk test results in pulmonary rehabilitation for patients with COPD. Int J Behav Med. 2012;19:39-47.

16. Kaptein AA, Scharloo M, Fischer MJ, et al. 50 years of psychological research on patients with COPD - road to ruin or highway to heaven? Respir Med. 2009;103:3-11.

17. Kaptein A, Meulenberg F, Smyth JM. Do art lovers make better doctors? Lancet Respir Med. 2013;1:769-770.

18. Scharloo M, Kaptein AA, Weinman J, et al. Illness perceptions, coping and functioning in patients with rheumatoid arthritis, chronic obstructive pulmonary disease and psoriasis. J Psychosom Res. 1988;44:573-585.

19. Scharloo M, Kaptein AA, Schlösser M, et al. Illness perceptions and quality of life in patients with chronic obstructive pulmonary disease. J Asthma. 2007;45:575-581.

20. Barlow J, Wright C, Sheasby J, Turner A, Hainsworth J. Selfmanagement approaches for people with chronic conditions: a review. Pat Educ Counsel. 2002;48:177-187.

21. Grant I, Heaton RK, McSweeny, et al. Neuropsychologic findings in hypoxemic chronic obstructive pulmonary disease. Arch Intern Med. 1982;142:1470-1476.

22. Guyatt GH, Berman LB, Townsend M, et al. A measure of quality of life for clinical trials in chronic lung disease. Thorax. 1987;42:773-778.

23. Peytremann-Brideveaux I, Staeger P, Brideveaux PO, Ghali WA, Burnand B. Effectiveness of COPD disease management programs: systematic review and meta-analysis. Am J Med. 2008;121: 433-443.
24. Ellrodt G, Cook DJ, Lee J, Cho M, Hunt D, Weingarten S. Evidence-based disease management. JAMA. 1997;278:1687-1692.

25. Bodenheimer T, Lorig K, Holman K, Grumbach K. Patient self-management of chronic disease in primary care. JAMA. 2002;288:2469-2475.

26. Adams SG, Smith PK, Allan PF, Anzueto A, Pugh JA, Cornell JE. Systematic review of the chronic care model in COPD prevention and disease. Arch Intern Med. 2007;167:551-561.

27. Spruit MA, Singh SJ, Garvey C, et al. An official American Thoracic Society/European Respiratory Society statement: key concepts and advances in pulmonary rehabilitation. Am J Respir Crit Care Med. 2013;188:e13-e64.

28. Effing T, Monninkhof EE, van der Valk PP, et al. Self-management education for patients with chronic obstructive pulmonary disease. Cochrane Database Syst Rev. 2007;(4):CD002990.

29. Walters JA, Turnock AC, Walters EH, Wood-Baker R. Action plans with limited patient education only for exacerbations of chronic obstructive pulmonary disease. Cochrane Database Syst Rev. 2010;(5): CD005074.

30. Rice KL, Dewan N, Bloomfield HE, et al. Disease management program for chronic obstructive pulmonary disease: a randomized controlled trial. Am J Respir Crit Care Med. 2010;182:890-896.

31. Koff PB, Jones RH, Cashman JM, Voelkel NF, Vandivier RW. Proactive integrated care improves quality of life in patients with COPD. Eur Respir J. 2009;33:1031-1038.

32. Bischoff EW, Akkermans R, Bourbeau J, van Weel C, Vercoulen JH, Schermer TR. Comprehensive self management and routine monitoring in chronic obstructive pulmonary disease patients in general practice: randomised controlled trial. $B M J$. 2012;345:e7642.

33. Bischoff EW, Hamd DH, Sedeno M, et al. Effects of written action plan adherence on COPD exacerbation recovery. Thorax. 2011;66: 26-31.

34. Trappenburg JC, Monninkhof EM, Bourbeau J, et al. Effect of an action plan with ongoing support by a case manager on exacerbation-related outcome in patients with COPD: a multicentre randomised controlled trial. Thorax. 2011;66:977-984.

35. Bucknall CE, Miller G, Lloyd SM, et al. Glasgow supported self-management trial (GSuST) for patients with moderate to severe COPD: randomized controlled trial. BMJ. 2012;344:e1060.

36. Effing TW, Bourbeau J, Vercoulen J, et al. Self-management programmes for COPD: moving forward. Chron Respir Dis. 2012;9:27-35.

37. Jonsdottir H. Self-management programmes for people living with chronic obstructive pulmonary disease: a call for a reconceptualisation. J Clin Nurs. 2013;22:621-637.

38. Nici L, Bontly TD, Zuwallack R, Gross N. Self-management in chronic obstructive pulmonary disease. Time for a paradigm shift? Ann Am Thorac Soc. 2014;11:101-107.

39. Effing T, van der Palen J, Frith P. Education in COPD self-management: only part of the game. Respirology. 2014;19:151-152.

40. Disler RT, Gallagher RD, Davidson PM. Factors influencing self-management in chronic obstructive pulmonary disease: an integrative review. Int J Nurs Stud. 2012;49:230-242.

41. Lenferink A, Frith P, van der Valk P, et al. A self-management approach using self-initiated action plans for symptoms with ongoing nurse support in patients with chronic obstructive pulmonary disease (COPD) and comorbidities: the COPE-III study protocol. Contemp Clin Trials. 2013;36:81-89.

42. Zwerink M, Brusse-Keizer M, van der Valk P, et al. Self management for patients with chronic obstructive pulmonary disease. Cochrane Database of Syst Rev. 2014;(3):CD002990

43. Lorig KR, Holman H. Self-management education: history, definition, outcomes, and mechanisms. Ann Behav Med. 2003;26:1-7.

44. Benzo R. Collaborative self-management in chronic obstructive pulmonary disease: learning ways to promote patient motivation and behavioral change. Chron Respir Dis. 2012;9:257-258.

45. Nici L, ZuWallack R. An official American Thoracic Society workshop report: the integrated care of the COPD patient. Proc Am Thorac Soc. 2012;9:9-18. 
46. Benzo R, Vickers K, Ernst D, Tucker S, McEvoy C, Lorig K. Development and feasibility of a self-management intervention for chronic obstructive pulmonary disease delivered with motivational interviewing strategies. J Cardiopulm Rehabil Prev. 2013;33:113-123.

47. Benzo RP. Mindfulness and motivational interviewing: two candidate methods for promoting self-management. Chron Respir Dis. 2013;10: $175-182$.

48. Kuo CC, Lin CC, Lin SY, Yang YH, Chang CS, Chen CH. Effects of self-regulation protocol on physiological and psychological measures in patients with chronic obstructive pulmonary disease. J Clin Nurs. 2013;22:2800-2811.

49. Eikelenboom N, van Lieshout J, Wensing M, Smeele I, Jacobs AE. Implementation of personalized self-management support using the self-management screening questionnaire SeMaS; a study protocol for a cluster randomized trial. Trials. 2013;14:336.

50. Cruz J, Brooks D, Marques A. Home telemonitoring effectiveness in COPD: a systematic review. Int J Clin Pract. 2014;68:369-378.

51. Pinnock H, Hanley J, McCloughan L, et al. Effectiveness of telemonitoring integrated into existing clinical services on hospital admission for exacerbation of chronic obstructive pulmonary disease: researcher blind, multicentre, randomised controlled trial. BMJ. 2013;347:f6070.

52. Cartwright M, Hirani SP, Rixon L, et al. Effect of telehealth on quality of life and psychological outcomes over 12 months (Whole Systems Demonstrator telehealth questionnaire study): nested study of patient reported outcomes in a pragmatic, cluster randomised controlled trial. BMJ. 2013;346:f653.

53. Moullec G, Ninot G. An integrated programme after pulmonary rehabilitation in patients with chronic obstructive pulmonary disease: effect on emotional and functional dimensions of quality of life. Clin Rehabil. 2010;24:122-136.

54. Chavannes NH, Grijsen M, van den Akker M, et al. Integrated disease management improves one-year quality of life in primary care COPD patients: a controlled clinical trial. Prim Care Respir J. 2009;18:171-176.

55. Blumenthal JA, Keefe FJ, Babyak MA, et al. Caregiver-assisted coping skills training for patients with COPD: background, design, and methodological issues for the INSPIRE-II study. Clin Trials. 2009;6:172-184.

56. Jowsey T, Pearce-Brown C, Douglas KA, Yen L. What motivates Australian health service users with chronic illness to engage in selfmanagement behaviour? Health Expect. 2014;17:267-277.

57. Coventry PA, Bower P, Keyworth C, et al. The effect of complex interventions on depression and anxiety in chronic obstructive pulmonary disease: systematic review and meta-analysis. PLoS One. 2013;8:e60532.

58. Wortz K, Cade A, Menard JR, et al. A qualitative study of patients' goals and expectations for self-management of COPD. Prim Care Respir J. 2012;21:384-391.

59. Gabriel R, Figueiredo D, Jácome C, Cruz J, Marques A. Day-to-day living with severe chronic obstructive pulmonary disease: towards a family-based approach to the illness impacts. Psychol Health. 2014;29:967-983.

60. Bourbeau J. The role of self-management in pulmonary rehabilitation. Semin Respir Crit Care Med. 2009;30:700-707.
61. Lacasse Y, Goldstein R, Lasserson TJ, Martin S. Pulmonary rehabilitation for chronic obstructive pulmonary disease. Cochrane Database Syst Rev. 2006;(4):CD003793.

62. Coventry PA, Hind D. Comprehensive pulmonary rehabilitation for anxiety and depression in adults with chronic obstructive pulmonary disease: systematic review and meta-analysis. $J$ Psychosom Res. 2007;63:551-565.

63. Arnold R, de Jongste MJ, Otten V, et al. Changes in personal control as a predictor of quality of life after pulmonary rehabilitation. Patient Educ Couns. 2006;61:99-108.

64. Vincent E, Sewell L, Wagg K, Deacon S, Williams J, Singh S. Measuring a change in self-efficacy following pulmonary rehabilitation: an evaluation of the praise tool. Chest. 2011;140:1534-1539.

65. Casaburi R. Activity promotion: a paradigm shift for chronic obstructive pulmonary disease therapeutics. Proc Am Thorac Soc. 2011;8: 334-337.

66. Ng LW, Mackney J, Jenkins S, Hill K. Does exercise training change physical activity in people with COPD? A systematic review and meta-analysis. Chron Respir Dis. 2012;9:17-26.

67. Egan C, Deering BM, Blake C, et al. Short term and long term effects of pulmonary rehabilitation on physical activity in COPD. Respir Med. 2012;106:1671-1679.

68. Hoogendoorn M, Feenstra TL, Hoogenveen RT, Rutten-van Mölken MP. Long-term effectiveness and cost-effectiveness of smoking cessation interventions in patients with COPD. Thorax. 2010;65:711-718

69. Beauchamp MK, Evans R, Janaudis-Ferreira T, Goldstein RS, Brooks D. Systematic review of supervised exercise programs after pulmonary rehabilitation in individuals with COPD. Chest. 2013;144: 1124-1133.

70. Broadbent E, Petrie KJ, Ellis CJ, Ying J, Gamble G. A picture of health - myocardial infarction patients' drawings of their hearts and subsequent disability. A longitudinal study. J Psychosom Res. 2004;57: $583-587$.

71. Luthy C, Cedraschi C, Pasquina P, Uldry C, Perron NJ, Janssens JP. Perception of chronic respiratory impairments in patients' drawings. J Rehab Med. 2013;45:694-700.

72. Brody H. Defining the medical humanities: three conceptions and three narratives. J Med Humanit. 2011;32:1-7.

73. Murray JF. Willing suspension of disbelief. Am J Respir Crit Care Med. 2013;187:465-467.

74. Kaptein AA, Meulenberg F, Smyth JM. A breath of fresh air: images of respiratory illness in novels, poems, movies, music, and paintings. $J$ Health Psychol. In press 2014.

75. Boulet LP, Bourbeau J, Skomro R, Gupta S. Major care gaps in asthma, sleep and chronic obstructive pulmonary disease: a road map for knowledge translation. Can Respir J. 2013;20:265-269.

76. Janssen DJ, Spruit MA, Wouters EF, Schols JM. Family caregiving in advanced chronic organ failure. J Am Med Dir Assoc. 2012;13: 394-399.

77. Perez X, Wisnivesky JP, Lurslurchachai L, Kleinman LC, Kronish IM. Barriers to adherence to COPD guidelines among primary care providers. Respir Med. 2012;106:374-381.

78. Williamson JM, Skinner CI, Hocken DB. Death and illness as depicted in the media. Int J Clin Pract. 2011;65:547-551.

International Journal of COPD

\section{Publish your work in this journal}

The International Journal of COPD is an international, peer-reviewed journal of therapeutics and pharmacology focusing on concise rapid reporting of clinical studies and reviews in COPD. Special focus is given to the pathophysiological processes underlying the disease, intervention programs, patient focused education, and self management protocols.

\section{Dovepress}

This journal is indexed on PubMed Central, MedLine and CAS. The manuscript management system is completely online and includes a very quick and fair peer-review system, which is all easy to use. Visit http://www.dovepress.com/testimonials.php to read real quotes from published authors. 